\title{
REPRESENTASI IDENTITAS CILEMBU PADA DESAIN IDENTITAS VISUAL ES KRIM UBIBU
}

\author{
Brian Alvin Hananto \\ Universitas Pelita Harapan
}

\begin{abstract}
Artikel ini akan membahas sebuah proses perancangan yang dilakukan dalam konteks perkuliahan di Program Studi Desain Komunikasi Visual Universitas Pelita Harapan. Perancangan yang dilakukan adalah perancangan sistem identitas visual terhadap produk es krim UBIBU, dimana produk tersebut menggunakan ubi Cilembu sebagai bahan dasarnya. Ubi Cilembu sendiri telah lama menjadi sebuah produk khas dari desa Cilembu, dimana keberadaan ubi tersebut dapat dikatakan sebagai identitas yang tidak terpisahkan dari Cilembu. Keunikan dari relasi antara ubi dan desa Cilembu sendiri diperkaya dengan adanya mitos mengenai seorang pangeran yang mengutuk selain Cilembu agar tidak dapat menghasilkan ubi semanis Cilembu. Dengan menggunakan mitos desa Cilembu sebagai konsep desain, desainer identitas visual es krim UBIBU ini mencoba untuk merepresentasikan identitas dari Cilembu dalam desainnya. Perancangan yang mengadopsi lima tahapan perancangan Alina Wheeler untuk branding ini menghasilkan sebuah sistem identitas visual yang komprehensif, yang kemudian diterapkan pada desain kemasan, desain media promosi dan desain merchandisenya. Hasil perancangan yang dibahas dalam artikel ini diharapkan dapat menjadi studi kasus dan referensi terhadap perancangan yang menggunakan identitas sebagai dasar perancangannya.
\end{abstract}

Keywords: identitas visual, representasi identitas, branding, desain kemasan, cilembu

Abstract. This paper will discuss a design process in the context of lecturing in the Visual Communication Design Study Programme at Universitas Pelita Harapan. The design we do is a visual identity system for UBIBU ice cream products, where Cilembu sweet potatoes is used as its basic ingredient. sweet potatoes itself has long been a typical product of the village of Cilembu, where the existence of the Cilembu sweet potatoes can be said to be an inseparable identity from Cilembu. The uniqueness of the relationship between sweet potatoes and the village of Cilembu is enriched by a myth about a prince who curses except Cilembu in order not to produce sweet potatoes as sweet as Cilembu. By using the myth of the village of Cilembu as a design concept, this UBIBU ice cream visual identity designer tries to represent the identity of Cilembu in its design. The design which adopts the five stages of Alina Wheeler's design for branding results in a comprehensive visual identity system, which is then applied to packaging design, promotional media design and merchandise design. The design results discussed in this paper are expected to be a case study and a reference about how to use identity as the basis for the design.

Keywords: visual identity, identity representation, branding, packaging design, cilembu

Correspondence author: Brian Alvin Hananto, betha.almanfaluthi@kalbis.ac.id, Tangerang, Indonesia

This work is licensed under a CC-BY-NC 


\section{Pendahuluan}

\section{Latar Belakang}

Sebelum terjun ke dalam pembahasan lebih lanjut, penulis merasa perlu menjelaskan konteks dari proses perancangan dan juga tulisan ini. Proses perancangan yang akan dibahas dalam tulisan ini adalah proses perancangan yang dilakukan salah seorang mahasiswi Program Studi Desain Komunikasi Visual angkatan 2016 yang bernama Felicia Kristella. Proses perancangan ini Kristella lakukan dalam perkuliahan dalam mata kuliah Studio Utama 3, dimana dalam mata kuliah tersebut, Program Studi Desain Komunikasi Visual Universitas Pelita Harapan bekerjasama dengan Program Studi Teknologi Pangan Universitas Pelita Harapan. Program Studi Desain Komunikasi Visual Universitas Pelita Harapan diminta untuk membantu mengembangkan identitas visual dan desain kemasan dari produk-produk yang telah dikembangkan oleh Program Studi Teknologi Pangan Universitas Pelita Harapan yang akan dipamerkan dalam acara tahunan mereka, Food Explore yang kesebelas. Melihat bagaimana produk yang dikembangkan merupakan sebuah produk yang unik, dan perancangan yang dilakukan oleh Kristella juga memiliki daya tarik tersendiri, penulis memutuskan untuk melihat lebih dalam mengenai proses perancangan yang dilakukan oleh Kristella, dan membahasnya dalam artikel ini.

\section{Ubibu dan Cilembu}

Produk yang menjadi fokus perancangan adalah sebuah es krim yang diberi nama UBIBU. UBIBU sendiri adalah singkatan dari ubi Cilembu, dimana es krim UBIBU memang memiliki bahan dasar ubi Cilembu. Ubi Cilembu merupakan sebuah umbi yang kekhasan warna kuning keemasan dan memiliki rasa manis seperti madu (Mahmudatussa'adah). Persentase atau kadar gula dari ubi Cilembu juga dapat dikatakan lebih tinggi dibandingkan ubi jalar lainnya; hal inilah yang menyebabkan ubi Cilembu dikatakan ubi yang sangat manis (Hidayat et al.; Mahmudatussa'adah).

Ubi Cilembu sendiri merupakan sebuah produk agrikultur unggulan dari desa Cilembu, namun potensinya belum banyak dikembangkan karena kurangnya perhatian pemerintah (Kunjana). Ubi Cilembu sendiri telah dipatenkan sebagai produk khas Cilembu Sumedang (JPNN). Rasa manis ubi Cilembu sendiri memang tidak bisa didapatkan oleh Ubi dari tempat lain (Mahmudatussa'adah). Upaya untuk mereproduksi ubi dengan kaliber seperti ubi Cilembu diluar Sumedang sendiri tidak dapat dilakukan walaupun menggunakan benih yang sama.

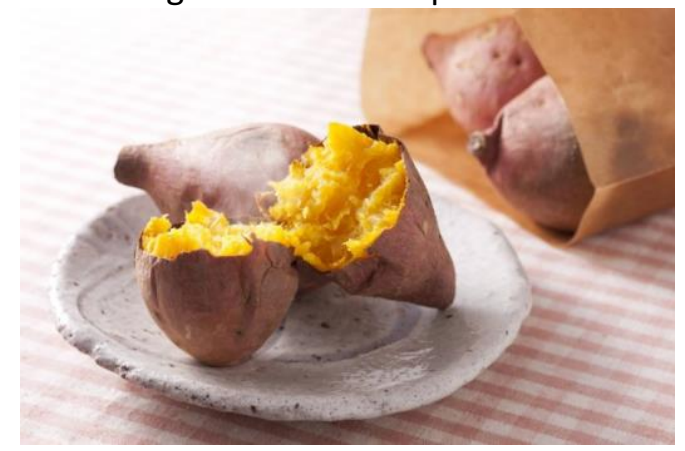

Gambar 1 Ubi Cilembu (Sumber: Sahabatnestle.co.id)

Pertanyaan mengapa rasa manis ubi Cilembu hanya didapatkan oleh ubi yang ditanam di Cilembu menjadi sebuah pertanyaan yang mendorong banyak ilmuwan untuk meneliti fenomena tersebut. Mulai dari argumentasi terkait struktur tanah sampai komposisi bakteri Cilembu menjadi jawaban dari mengapa ubi dari Cilembu itu manis tidak seperti ubi lainnya 
(Budianto; Expobia.id). Namun jika ditanyakan kepada masyarakat lokal, tidak sedikit yang memberikan jawaban yang menyangkut mitos desa Cilembu.

Alkisah, seorang pangeran menyamar menjadi seorang kakek tua renta yang pergi mengunjungi daerah-daerah kekuasaannya. Dalam perjalanannya, ia banyak ditolak oleh warga setempat, hingga akhirnya ia sampai pada desa Cilembu. Ketika ia sampai di Cilembu, warga setempat tengah memanen ubi, dan membagikan ubinya kepada sang pangeran yang tengah menyamar itu. Kagum dengan rasa manis ubi dari desa Cilembu itu dan juga tersentuh atas kebaikan warganya, sang pangeran kemudian mengutuk daerah sekitarnya untuk tidak pernah mendapatkan ubi semanis ubi dari desa Cilembu (DesaCilembu.com; Expobia.id).

Latar belakang atau mitos inilah yang kemudian diangkat oleh Kristella sebagai gagasan dasar dari komunikasi visual dari es krim UBIBU. Dengan menggunakan mitos ini sebagai sebuah cerita, Kristella mengemas es krim UBIBU dengan narasi yang menuntun audiens dan konsumen untuk mendalami kisah dibalik ubi Cilembu melalui es krim UBIBU.

\section{Metode}

Dalam proses perancangan UBIBU, dilakukan lima tahapan perancangan yang mengacu pada lima proses branding oleh Wheeler (Gambar 2). Pada tahapan pertama, desainer melakukan riset terhadap entitas atau produk yang perlu diketahui oleh desainer; riset yang dilakukan dapat dilakukan guna mendalami atau mempelajari kekhasan ataupun identitas dari produk tersebut dan/atau konteks yang melingkupi entitas tersebut. Tahapan kedua adalah tahapan yang memilah dan juga menyimpulkan ide atau gagasan dalam program branding tersebut. Tahapan ketiga adalah perancangan identitas visual atau brand identity yang berupa logo dan juga elemen-elemen visual yang terkait. Tahapan keempat adalah pembuatan media atau titik sentuh konsumen terhadap entitas. Tahapan terakhir adalam mengelola aset-aset desain dalam

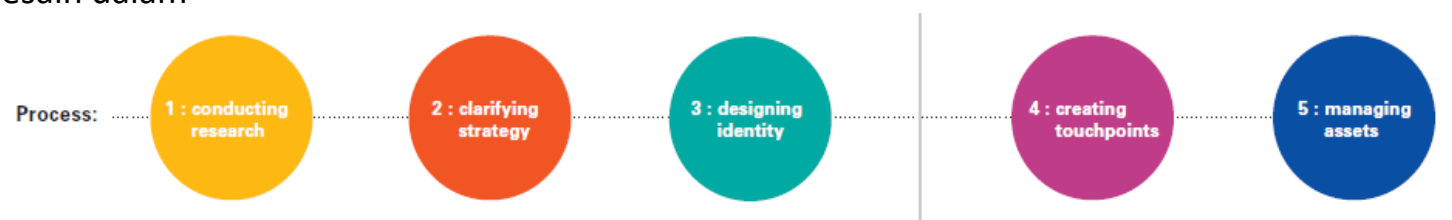

Gambar 2 Tahapan Perancangan Berdasarkan Tahapan Alina Wheeler. (Sumber: Wheeler)

Adapun tahapan-tahapan lebih praktis yang dilakukan oleh Kristella dalam perancangan di dalam mata kuliah Studio Utama 3 adalah sebagai berikut:

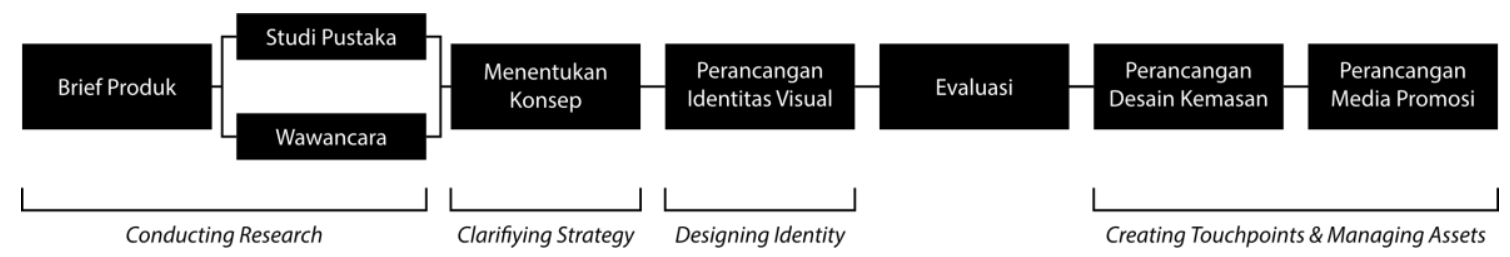

Gambar 3 Tahapan Perancangan Berdasarkan Struktur Mata Kuliah Studio Utama 3.

(Sumber: Dokumentasi Penulis, 2019)

Proses perancangan dimulai dengan conducting research dalam bentuk mendapatkan brief atau keterangan mengenai produk yang kemudian dilanjutkan dengan proses wawancra 
dan juga studi pustaka guna memperkaya informasi dan data mengenai produk. Pada tahap inilai Kristella mendapatkan pustaka dan juga data terkait mitos Desa Cilembu. Ide-ide tersebut kemudian dikembangkan menjadi sebuah konsep perancangan dalam tahapan clarifiying strategy. Setelah gagasan mengenai pendekatan visual didapatkan, Kristella mulai membuat perancangan identitas visual yang dimulai dengan perancangan logo dari identitas visual tersebut. Tahap designing identity juga dilanjutkan dengan menentukan palet warna dan juga membangun ilustrasi guna memvisualisasikan narasi mengenai mitos Desa Cilembu tersebut. Setelah mendapatkan identitas visual, diadakan evaluasi dengan format forum group discussion dengan pihak Program Studi Teknologi Pangan Universitas Pelita Harapan untuk mendapatkan masukan-masukan terkait desain yang telah dihasilkan. Pada tahap creating touchpoints dan managing assets, Kristella mengembangkan identitas visual yang telah dihasilkan pada mediummedium desain lainnya seperti desain kemasan dan juga desain media promosi.

\section{Hasil dan Pembahasan}

\section{Studi Literatur}

Identitas dan Brand

Identitas berasal dari bahasa Latin 'idem' yang berarti sama. Identitas sendiri menunjukkan relasi dari suatu hal yang persistent, atau menetap, dan juga proses membagikan karakter esensial itu secara terus menerus (Dundes). Hal ini mengindikasikan bahwa identitas sendiri merupakan sebuah 'obyek' yang melekat kepada entitas dan yang secara aktif terusmenerus memancarkan dan membagikan keberadaannya kepada orang-orang lain. Ketika sebuah identitas tidak dapat dilihat atau dirasakan oleh orang-orang sekitarnya, maka hal tersebut perlu dipertanyakan kembali apakah hal tersebut memang sebuah identitas.

Komponen dari identitas sendiri dapat berupa relasi sosial dan peran dimana entitas tersebut berada (Oyserman et al.). Hal ini sejalan dengan apa yang telah dinyatakan oleh Dundes, dimana identitas tidak bisa dilihat secara parsial dan spesifik, namun harus dilihat secara menyeluruh dan memiliki komparasi eksternal. Seseorang yang dinilai berbeda dari orang-orang disekitarnya memiliki 'perbedaan' tersebut sebagai identitasnya; dan ketika perbedaan tersebut secara konsisten dirasakan dan dipahami oleh sekelilingnya, maka identitas tersebut menjadi sebuah identitas yang kental dan melekat.

Identitas dapat merujuk kepada apa yang telah terjadi sebelumnya, apa yang nyata sekarang ini, dan juga apa yang dikehendaki oleh entitas itu dikemudian hari (Oyserman et al.). Seseorang tidak bisa memilih apa yang telah menjadi identitasnya, namun ia dapat menentukan citra apa yang ia tunjukkan. Hal itu dikarenakan pemahaman mengenai identitas dapat membantu seseorang dan memotivasi seseorang untuk memahami dirinya lebih lagi.

Marty Neumeier dari The Brand Gap mengungkapkan bahwa brand adalah penilaian dan juga perasaan seseorang terhadap sebuah produk, servis ataupun perusahaan (Wheeler). Dengan mengacu terhadap pandangan Neumeier dan Oyserman, kita dapat melihat bahwa relasi dari identitas dan juga brand dapat dilihat dalam Gambar 4 berikut:

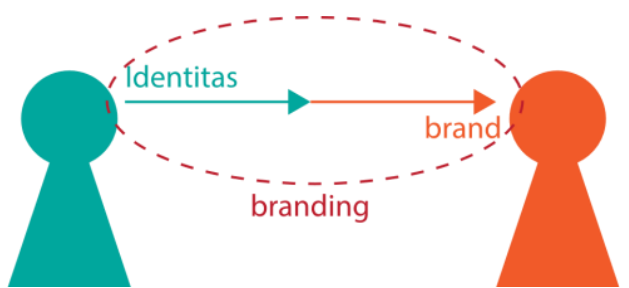

Gambar 4 Identitas, Brand, dan Branding. (Sumber: Dokumentasi Penulis, 2019) 
Seseorang yang memiliki identitas adalah seseorang yang memiliki penilaian dan pemahaman mengenai kondisinya dan juga kesadaran mengenai apa citra yang ingin ia tampilkan. Brand sendiri adalah penilaian seseorang terhadap orang atau entitas lain. Dengan demikian, kita dapat menyimpulkan bahwa identitas sebuah produk yang kuat juga berarti brand produk tersebut kuat dimata audiensnya.

Branding adalah sebuah proses untuk membangun kesadaran seorang konsumen dengan harapan hal tersebut dapat turut membangun kesetiaan konsumen tersebut (Wheeler). Upaya seseorang untuk meningkatkan penilaian orang terhadap identitasnya juga merupakan bentuk branding. Kegiatan branding yang kontekstual dengan peran atau tanggung jawab desainer adalah mengimplementasikan brand identity kepada medium-medium desain yang disebut sebagai brand touchpoints. Brand Touchpoints adalah sebuah fase, momen, ataupun obyek yang memungkinkan adanya interaksi antara konsumen dan juga entitas ( "Perancangan Identitas Visual Dan Desain Kemasan Produk Makanan (Studi Kasus: Fibble)"; Wheeler). Brand touchpoints dapat dikatakan sebagai sebuah representasi atau manifestasi dari entitas tersebut yang dapat dipersepsikan oleh konsumen guna 'mengalami' entitas.

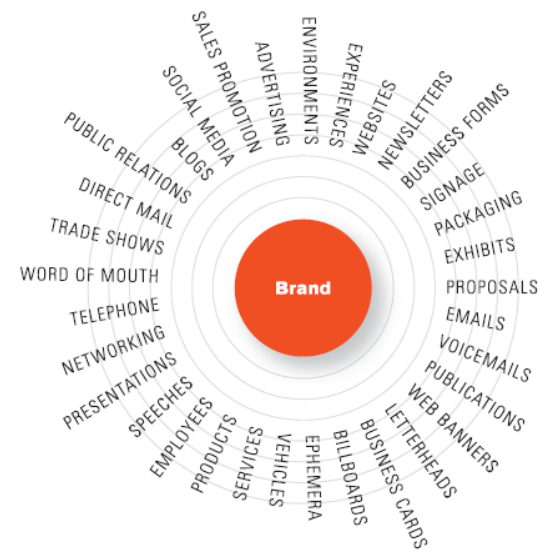

Gambar 5 Brand Touchpoints. (Sumber: Wheeler)

\section{Perancangan Identitas Visual dalam Branding}

Dalam upaya memberikan rupa atau bentuk dari sebuah entitas kepada konsumennya, maka desainer merancang sesuatu yang dinamakan identitas visual atau brand identity. Identitas visual adalah penjabaran visual dari identitas sebuah entitas dalam bentuk logo dan juga aplikasi desain yang bersangkutan seperti kop surat, kartu nama, desain kemasan, dst (Landa). Dalam merancang sebuah identitas visual, dibutuhkan perancangan elemen-elemen visual yang kemudian dapat digunakan untuk membangun sebuah sistem visual yang koheren (Wheeler).

Dalam merancang elemen visual, seorang desainer dapat mengangkat karakteristik atau aspek-aspek terkait entitas tersebut dan menggunakannya sebagai landasan atau konsep dalam perancangan (Hananto "Perancangan Identitas Visual Dan Desain Kemasan Produk Makanan (Studi Kasus: Fibble)"). Elemen-elemen visual yang dihasilkan dapat berupa elemen-elemen seni seperti bentuk ataupun warna, maupun elemen-elemen desain grafis, yakni gambar ataupun huruf. Identitas visual yang baik adalah identitas visual yang konsisten, dimana salah satu elemennya menjadi sebuah variabel desain yang dapat diimplementasikan secara fleksibel pada aplikasi-aplikasinya (Hananto "Identitas Visual Digital Brand Dalam Sosial Media").

Implementasi dari identitas visual atau brand identity pada medium-medium desain atau brand touchpoints adalah bagian pivotal dalam proses branding. Setiap medium desain memiliki karakteristik atau natur yang berbeda-beda yang perlu diperhatikan ketika 
mengimplementasikan identitas visual kedalam media tersebut. Pemahaman desainer mengenai medium itu ibarat pemahaman seorang seniman terhadap kanvasnya, dimana ia perlu memahami limitasi dari medium guna menghasilkan desain yang 'berfungsi' dengan efektif dan juga efisien.

\section{Pembahasan Konsep Perancangan}

Dalam perancangan yang dilakukan oleh Kristella, setelah melakukan studi mengenai produk es krim UBIBU, ia memutuskan untuk secara fokus terhadap bahan dasar dari es krim UBIBU yang memang merupakan kekhasan dari es krim UBIBU. Kristella kemudian mengangkat mitos dari mengapa Ubi Cilembu itu manis. Mitos dari Desa Cilembu itu merupakan sebuah pengetahuan dan cerita yang dikenal oleh warga-warganya, dan dapat dikatakan merupakan sebuah identitas dari Desa Cilembu yang kemudian ia ilustrasikan. Ilustrasi dari Kristella kemudian ia gunakan sebagai elemen utama dari identitas visual es krim UBIBU.

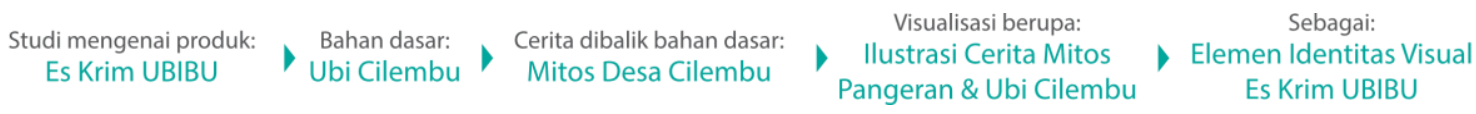

Gambar 6 Pemetaan Konsep Identitas Visual Es Krim UBIBU. (Sumber: Dokumentasi Penulis, 2019)

Perancangan Identitas Visual dan Aplikasi Es Krim UBIBU

Eksplorasi Logo

Pada tahap eksplorasi logo, dilakukan tahapan-tahapan sebagai berikut:

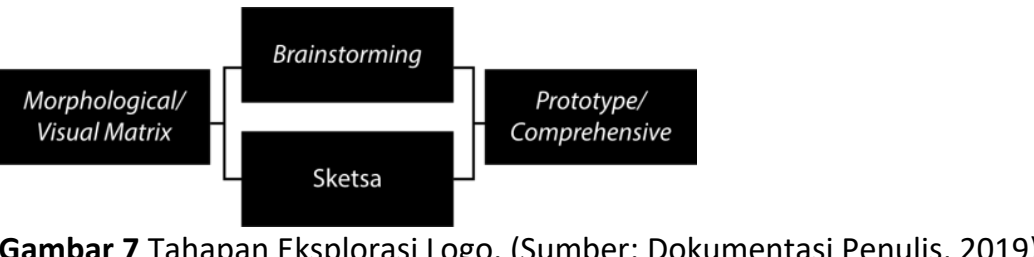

Eksplorasi logo digunakan guna melihat potensi-potensi pengembangan desain secara umum. Proses eksplorasi logo sendiri dimulai dengan menggunakan morphological matrix, sebuah teknik eksplorasi visual yang dengan cara mencacah kata kunci desain dan memvisualisasikan tiap kata kunci tersebut sebelum nanti elemen-elemen yang terpisah itu dipadukan menjadi alternatif-alternatif desain ( Fenech). Setelah melakukan eksplorasi dengan menggunakan morphological matrix, Kristella melakukan brainstorming untuk mendapatkan bentuk-bentuk berdasarkan hasil dari morphological matrix tersebut. Selain itu, Kristella juga melakukan sketsa guna menambah eksplorasi dan mengembangkan potensi-potensi yang sebelumnya sudah tampak pada matrix yang dihasilkan. Hasil akhir dari tahapan eksplorasi logo ini adalah sebuah prototype logo, dimana logo sudah dibuat secara digital. Pada tahap ini, logo masih bisa saja berubah untuk mengakomodir keperluan-keperluan lain atau masukan-masukan sembari proses perancangan berjalan. 


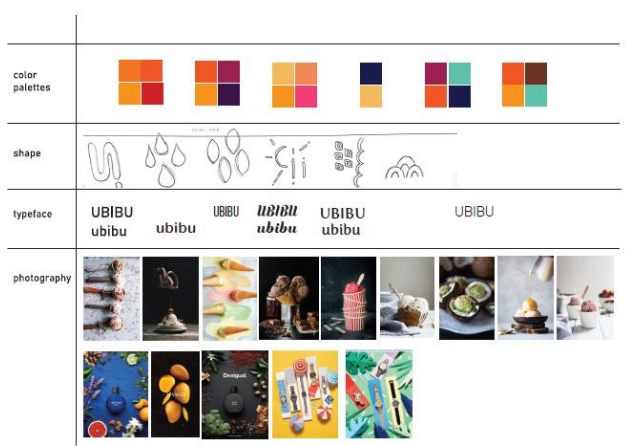

Gambar 8 Salah Satu Bagian dari Morphological Matrix karya Felicia Kristella.

(Sumber: Dokumentasi Penulis, 2019)

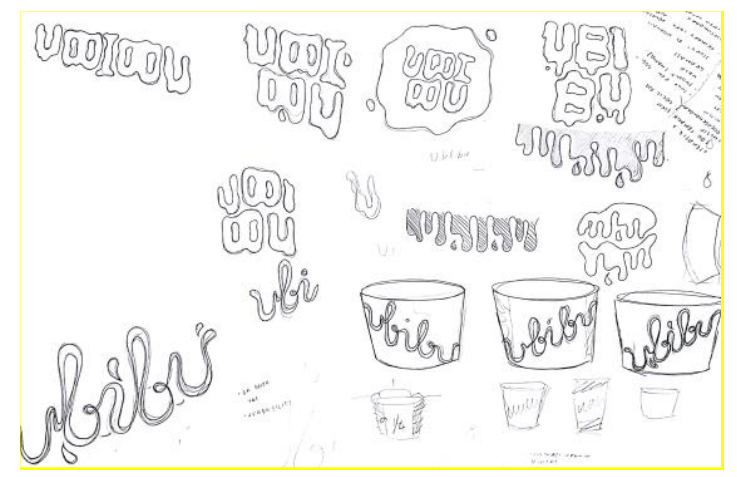

Gambar 9 Salah Satu Sketsa Felicia Kristella untuk Logo Es Krim UBIBU.

(Sumber: Dokumentasi Penulis, 2019)

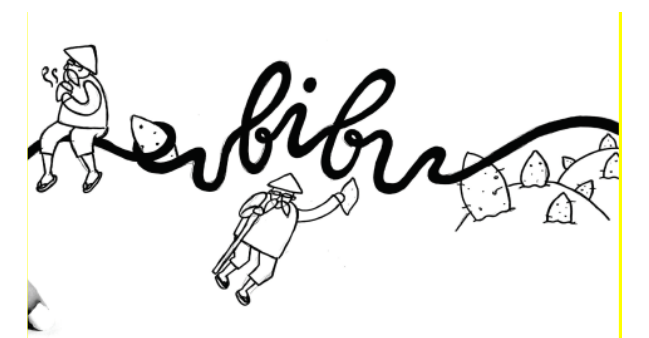

Gambar 10 Sketsa Lanjut oleh Felicia Kristella.

(Sumber: Dokumentasi Penulis, 2019)

Alternatif logo yang dikembangkan adalah alternatif logo yang mencoba menkomunikasikan bentuk fluid dari sebuah es krim untuk memberikan kesan 'enak'. Tulisan dari logo juga dibuat dengan handwritten untuk mengejar eksplorasi dan menciptakan bentuk yang memiliki rima dan juga kesatuan visual. Selain itu, perpanjangan goresan huruf 'u' dibuat membentang panjang agar dapat diintegrasikan kelak dalam desain kemasannya. Perpanjangan huruf ' $u$ ' juga dilakukan untuk menciptakan garis horizon dan tumpuan dari elemen-elemen lain seperti elemen ilustrasi. Elemen garis yang tercipta dari perpanjangan huruf ' $u$ ' juga dibuat fleksibel dan dinamis, dengan pemahaman bahwa bentuknya dapat berubah-ubah mengikuti format dari medium tempat logo tersebut bernaung. Pendekatan ini umumnya disebut sebagai desain logo untuk dynamic branding. Dynamic Branding adalah sebuah identitas dari entitas yang mampu berubah, bergerak dan juga fleksibel (Bardell). Perlu diingat bahwa pada tahap ini, logo masih dapat diubah dan disempurnakan kembali. Perubahan yang dilakukan juga sifatnya tidak mengubah konsep dari logo, namun untuk memperbaiki kualitas formal dari logo tersebut, seperti isu mengenai readability \& legibility. Legibility adalah prinsip kejelasan dari sebuah 
huruf, apakah huruf itu dapat dibedakan atau tidak. Readability adalah prinsip keterbacaan, umumnya dari kumpulan huruf seperti kata, kalimat, paragraf dst. (Hananto "Tinjauan Karya Desain Poster Quotes Dalam Mata Kuliah Tipografi Dasar"; Jury).

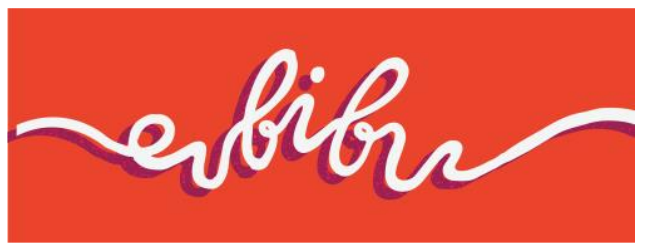

Gambar 11 Logo Digital Es Krim UBIBU oleh Felicia Kristella.

(Sumber: Dokumentasi Penulis, 2019)

\section{Pemilihan Warna}

Warna yang digunakan untuk identitas visual dari es krim UBIBU dipilih dari warna ubi Cilembu, dimana warna-warna yang didapatkan adalah warna merah, kuning, oranye dan juga coklat. Warna-warna tersebut juga merupakan kelompok warna-warna hangat, yang memiliki daya stimulus yang baik dan dipercaya sebagai warna-warna yang dapat menggugah selera makan konsumen (Samara).

Warna-warna tersebut kemudian dikembangkan menjadi sebuah palet warna dengan dasar pertimbangan skema warna analogous, skema warna analogous adalah skema warna dimana warna-warnanya bersebelahan dalam lingkar warna (Samara). Skema warna tersebut dipilih untuk menghasilkan harmoni dalam desain yang minim kontras. Elemen dengan warna paling kontras dalam desain es krim UBIBU adalah logo es krim UBIBU; hal tersebut dilakukan karena logo dirasa merupakan elemen paling penting dan perlu ditonjolkan.

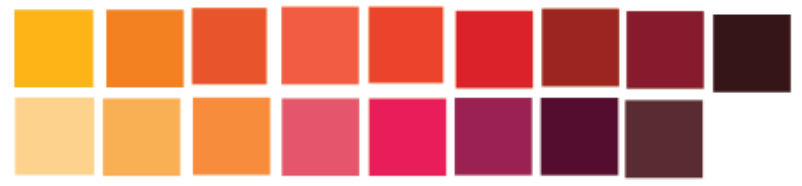

Gambar 12 Palet Warna Utama untuk Identitas Visual Es Krim UBIBU.

(Sumber: Dokumentasi Penulis, 2019)

Guna menambahkan visual interest dalam ilustrasi, Kristella juga mengembangkan palet warna sekunder yang digunakan sebagai aksen dalam ilustrasi, khususnya pada tanaman. Palet warna sekunder ini terdiri dari warna hijau dan turunannya. Warna hijau dipilih karena merupakan warna natural dari tanaman dan juga dapat mencerminkan kesan segar dan sehat (Samara).

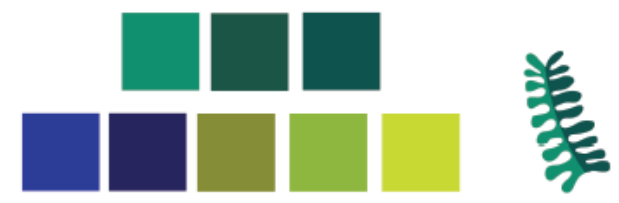

Gambar 13 Palet Warna Sekunder untuk Identitas Visual Es Krim UBIBU.

(Sumber: Dokumentasi Penulis, 2019)

\section{Ilustrasi}

Untuk perancangan ilustrasi sebagai elemen dari identitas visual, Kristella membangun ilustrasinya dari logo yang telah ia buat. Ilustrasi yang ia hasilkan untuk es krim UBIBU 
mengangkat sang pameran yang telah menjelma sebagai kakek tua, pemandangan dari desa Cilembu, dan ubi Cilembu itu sendiri. Ilustrasi dibuat dengan gaya ilustrasi flat design, dimana gaya ilustrasi tersebut dinilai merupakan salah satu gaya ilustrasi yang banyak ditemui secara umum. Dengan demikian, ilustrasi dari mitos desa Cilembu sendiri dapat disampaikan dengan lebih familiar dengan menggunakan gaya ilustrasi kontemporer yang sudah dikenal orang-orang. Flat Design adalah sebuah pendekatan visual minimalistik yang mengedepankan fungsi (May). Secara umum, flat design banyak ditemukan pada desain UI \& UX, namun pendekatan visual tersebut merambah kepada aspek-aspek lain seperti ilustrasi. Dalam ilustrasi, flat design adalah pendekatan visual yang menyederhanakan ilustrasi dengan tidak menggunakan gradasi, tekstur atau efek-efek tiga dimensi.

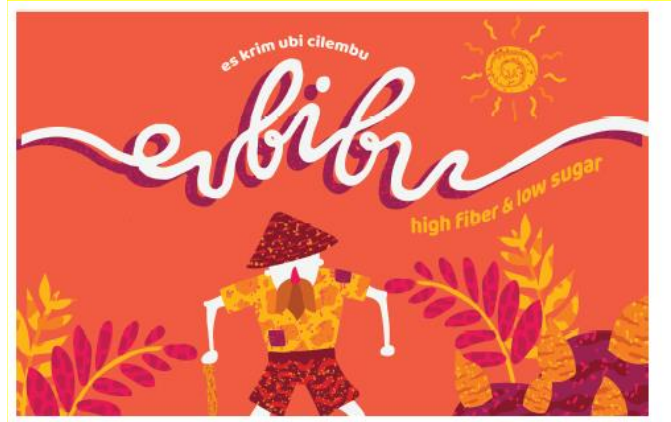

Gambar 14 Ilustrasi Mitos Desa Cilembu pada Kemasan Es Krim UBIBU oleh Felicia Kristella. (Sumber: Dokumentasi Penulis, 2019)

\section{Aplikasi pada Desain Kemasan}

Pada desain kemasan, Kristella merancang permukaan pada kemasan es krim cup pada umumnya. Bidang yang masuk dalam area visual Kristella adalah tutup cup dan juga dinding cup kemasan es krim (Gambar 15 dan Gambar 16).

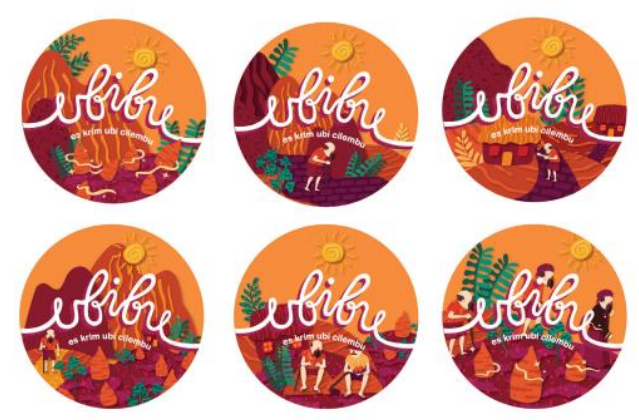

Gambar 15 Visual Kemasan Tutup Cup Es Krim UBIBU oleh Felicia Kristella.

(Sumber: Dokumentasi Penulis, 2019) 


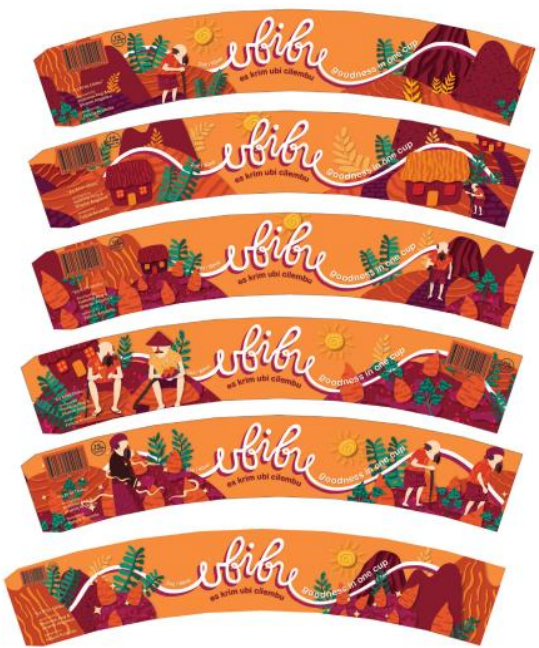

Gambar 16 Visual Kemasan Dinding Cup Es Krim UBIBU oleh Felicia Kristella. (Sumber: Dokumentasi Penulis, 2019)

Adapun visualisasi dari desain kemasan ini memiliki varian guna menggambarkan secara utuh mitos desa Cilembu. Hal ini dilakukan ketika konsumen mendapatkan dua produk es krim UBIBU, ada kemungkinan besar bahwa ia akan memperoleh kemasan dengan ilustrasi yang berbeda. Hal ini dipercaya dapat menciptakan rasa penasaran dan juga ketertarikan konsumen terhadap visual es krim UBIBU.

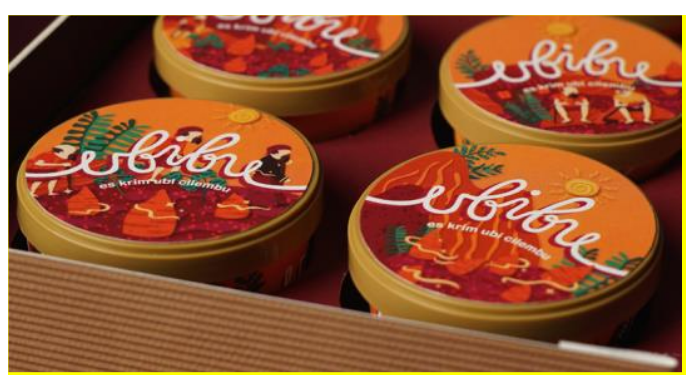

Gambar 17 Foto Desain Kemasan Es Krim UBIBU oleh Felicia Kristella.

(Sumber: Dokumentasi Penulis, 2019)

\section{Aplikasi pada Media Promosi Digital}

Untuk aplikasi identitas visual pada media promosi, Kristella membuat media Instagram sebagai salah satu media yang digunakan sebagai brand touchpoints-nya (Gambar 18). 

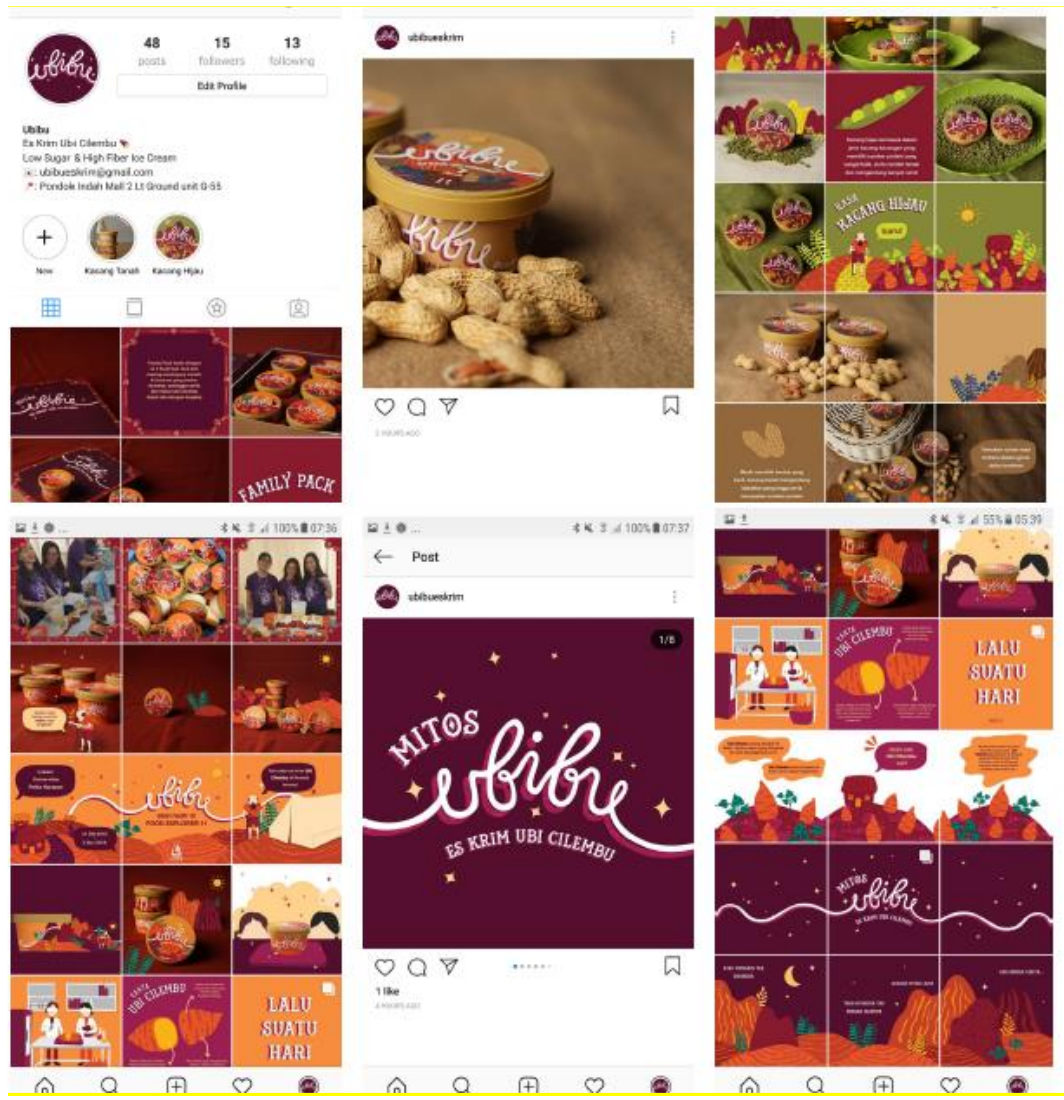

Gambar 18 Tampilan Media Promosi Instagram Es Krim UBIBU oleh Felicia Kristella.

(Sumber: Dokumentasi Penulis, 2019)

Dapat dilihat bahwa penggunaan elemen-elemen visual dalam media Instagram ini menuntut penggunaan elemen-elemen identitas visual secara independen dan juga secara kolektif. Pada beberapa post cukup menggunakan elemen fotografi ataupun ilustrasi saja, namun pada beberapa post diperlukan gabungan dari elemen-elemen visual tersebut. Variasi dari pemakaian elemen ini dipercaya mampu menciptakan konsistensi yang tidak monoton. Selain itu, audiens dan juga konsumen dapat terus 'berinteraksi' dan 'melihat' es krim UBIBU dari berbagai tampilan yang koheren.

Salah satu karakteristik atau trend desain post untuk feed Instagram adalah menggunakan beberapa modul grid Instagram dalam satu gambar. Hal ini menciptakan variasi ukuran dalam feed Instagram itu dan variasi ukuran tersebut juga dapat digunakan untuk menciptakan hirarki visual ketika feed Instagram itu dilihat secara utuh.

\section{Aplikasi pada Merchandise}

Ketika kita berbicara mengenai perancangan identitas visual untuk sebuah produk yang perlu dipromosikan, kita tidak bisa lepas pada merchandise. Merchandise sendiri merupakan sebuah medium yang tidak kalah kompleks untuk dirancang dan memiliki potensi sebagai brand touchpoints yang efektif. Selain menjadi sebuah insentif yang dibagikan kepada konsumen, merchandise juga dapat menjadi sebuah brand touchpoints yang dapat menyusup dalam kehidupan konsumen. Sebagai contoh, ketika seorang konsumen membeli atau memiliki sebuah tumbler dari sebuah entitas tertentu, ketika ia membawa tumbler tersebut, ia akan terus membawa bagian dari sang entitas. Akhirnya sang konsumen menjadi brand touchpoints ketika ia dilihat menggunakan tumbler tersebut oleh orang-orang lain. 
Kompleksitas dari perancangan merchandise terletak pada keberagaman bentuk dan format dari merchandise itu sendiri. Perlu dipahami bahwa merchandise adalah sebuah medium yang umumnya dapat digunakan dan fungsional. Selain itu, merchandise juga perlu memiliki visual yang menarik bagi konsumen agar mau digunakan dalam keseharian konsumen. Dengan demikian, kebutuhan dari sebuah sistem identitas visual yang fleksibel dan juga menarik untuk sebuah entitas diperlukan.

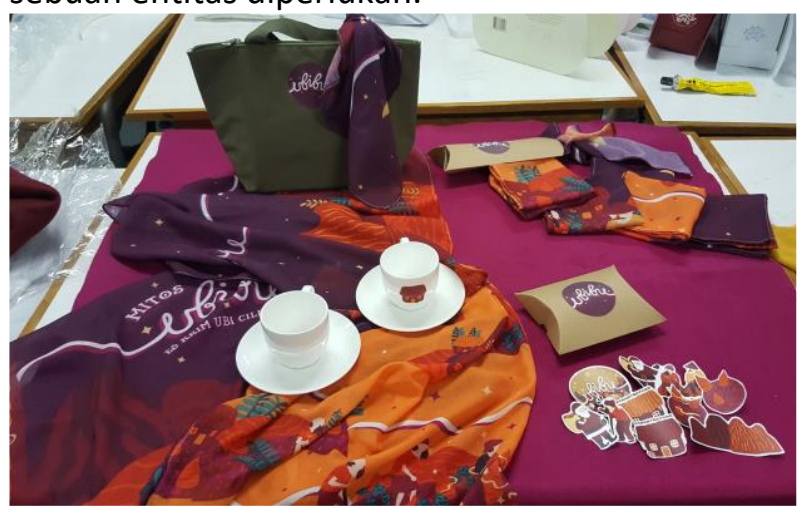

Gambar 19 Tampilan Berbagai Merchandise Es Krim UBIBU oleh Felicia Kristella.

(Sumber: Dokumentasi Penulis, 2019)

Dapat dilihat pada Gambar 19 bahwa elemen-elemen yang paling dominan es krim UBIBU yang digunakan lintas medium merchandise adalah elemen warna, garis dari logo dan juga ilustrasi. Pertimbangan untuk dapat fleksibel dan tetap sintaktik inilah yang diperhatikan sejak awal menentukan elemen-elemen untuk identitas visual dari es krim UBIBU dengan mengobservasi dan mencoba aplikasi dari identitas visual tersebut sedini mungkin. Dengan demikian, ketika ada medium-medium lain yang akan digunakan, es krim UBIBU sudah siap untuk menanamkan identitas visualnya pada medium tesebut.

\section{Evaluasi Perancangan}

Penulis awalnya tidak merencanakan melakukan evaluasi dampak perancangan secara formal, namun karena natur perancangan yang dilakukan dalam mata kuliah, maka terdapat momen-momen evaluasi terhadap desain yang terjadi secara impromptu. Dalam proses perkuliahan Studio Utama 3, terdapat beberapa momen ketika desain es krim UBIBU terekspos kepada publik (Seperti pada pameran, Gambar 21), dan dari perbincangan penulis dengan orang-orang tersebut, mayoritas responden yang berdiskusi dengan penulis mengakui bahwa mereka baru mengetahui mitos mengenai Desa Cilembu setelah melihat desain kemasan es krim UBIBU.

Ketika audiens melihat
Identitas Visual
Es Krim UBIBU $\begin{gathered}\text { Audiens juga melihat } \\ \text { Ilustrasi Cerita Mitos } \\ \text { Pangeran \& Ubi Cilembu }\end{gathered} \quad \begin{gathered}\text { Dan mempelajari mengenai } \\ \text { Mitos Desa Cilembu \& } \\ \text { Ubi Cilembu }\end{gathered} \begin{gathered}\text { yang merupakan } \\ \text { Identitas dari } \\ \text { Desa Cilembu, Sumedang }\end{gathered}$

Gambar 20 Bagaimana Audiens dapat Memahami Identitas Desa Cilembu, Sumedang dari Identitas Visual Es Krim UBIBU. (Sumber: Dokumentasi Penulis, 2019)

Dengan pemahaman bahwa mitos mengenai desa Cilembu dan Ubi Cilembu merupakan sebuah keunikan tersendiri bagi Desa Cilembu, dan hal itu secara tidak sadar terkomunikasikan juga dengan adanya kemasan dan identitas visual es krim UBIBU. Pengunjung yang sebelumnya tidak mengetahui keberadaan desa Cilembu dan juga ubi Cilembu menjadi terekspos dengan memakan es krim UBIBU dan melihat kemasannya. Hal ini merupakan sebuah dampak positif dan tidak terduga dari perancangan ini. 


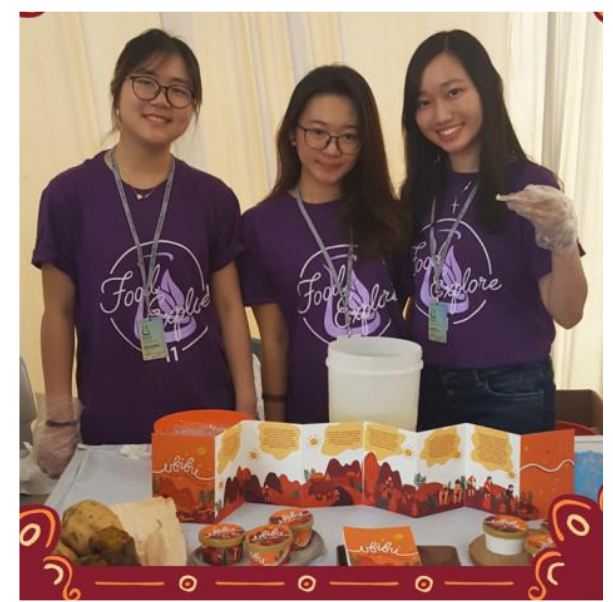

Gambar 21 Foto Mahasiswa Program Studi Teknologi Pangan dalam Pameran Food Explore dan Desain Es Krim UBIBU. (Sumber: Dokumentasi Penulis, 2019)

\section{Simpulan}

Berdasarkan perancangan dan juga evaluasi yang dilakukan, penulis memetakan relasi balik antara perancangan identitas visual es krim UBIBU dan juga Identitas dari desa Cilembu, Sumedang dalam Gambar 22 berikut:

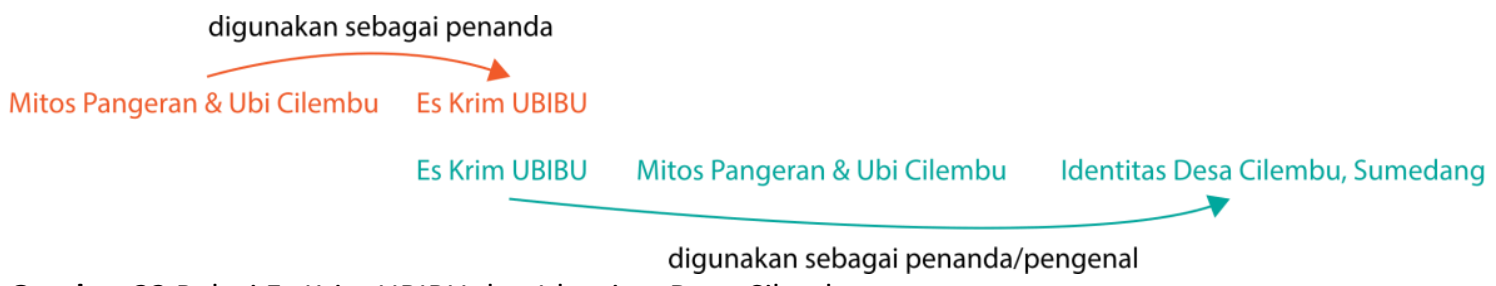

Gambar 22 Relasi Es Krim UBIBU dan Identitas Desa Cilembu.

(Sumber: Dokumentasi Penulis, 2019)

Mitos mengenai pangeran dan juga ubi Cilembu awalnya hanya digunakan sebagai basis dari perancangan identitas visual es krim UBIBU akhirnya kembali menjadi pesan yang dikomunikasikan dengan adanya desain dari es krim UBIBU. Melihat relasi dari identitas dan juga desain (Gambar 23), penulis merasa bahwa hal tersebut harusnya menjadi hal yang lumrah dan wajar saja terjadi ketika proses visualisasi dilakukan dengan benar dan tepat. Penulis juga menyadari bahwa hal tersebut juga dapat terjadi ketika desainer dapat menggali dan memilah dengan tepat inti atau identitas dari sebuah entitas. Dengan demikian ketika identitas tersebut di visualisasikan dengan benar, maka desain atau visual tersebut dapat menjadi penanda yang tepat bagi identitas tersebut.

\section{Identitas}

menjadi dasar

Desain

menjadi penanda

Gambar 23 Relasi Identitas dan Desain.

Identitas

(Sumber: Dokumentasi Penulis, 2019) 
Kesimpulan lain yang sifatnya praktis dan menyentuh aspek formal desain adalah kebutuhan mendasar dari perancangan sebuah logo juga perlu dipertimbangkan ketika merancang keseluruhan identitas visual:

1. Fleksibilitas, sebuah sistem identitas visual perlu dapat digunakan lintas format dan lintas medium. Hal ini dikarenakan banyak sekali bentuk brand touchpoints yang berkembang, dan sebuah sistem identitas visual yang baik harus dapat mengakomodir hal-hal tersebut.

2. Keberagaman, sebuah sistem identitas visual perlu memiliki elemen-elemen yang dapat digunakan secara terpisah maupun ketika dipadukan dan menyatu. Elemen-elemen visual yang beragam ini diperlukan untuk mengakomodir berbagai bentuk brand touchpoints dan juga untuk menghasilkan berbagai tampilan yang beragam namun tetap koheren dan sintaktik.

3. Keunikan, pada dasarnya sebuah identitas visual perlu unik dengan harapan hal tersebut dapat menarik audiens hingga menjadi konsumen. Keunikan dari sebuah identitas visual diharapkan muncul dari identitas dari entitas itu sendiri, bukan sebuah rekayasa atau konstruksi manipulatif yang akhirnya bukan bagian atau bukan representasi dari entitas itu.

Penulis ingin memberikan saran terkait perancangan identitas visual berdasarkan kesimpulan yang penulis dapatkan:

1. Ketika merancang sebuah sistem identitas visual, mulailah dengan mempertimbangkan brand touchpointsnya, atau pada medium apa sajakah identitas visual ini perlu muncul. Hal tersebut terkadang memberikan 'batasan-batasan' ketika mendesain, namun ketika perancangan dapat memenuhi kriteria atau batasan tersebut, hasil desain juga umumnya lebih kontekstual.

2. Ketika merancang sebuah sistem identitas visual, diperlukan konsistensi dan koherensi. Ketika kita memulai dengan perancangan sebuah logo, selanjutnya kita dapat menggali atau mengekstrak kembali elemen-elemen seni rupa yang ada dalam logo untuk dikembangkan menjadi elemen identitas visual. Sebagai contoh:

a. Bentuk atau jenis tulisan dalam logo dapat menjadi elemen huruf dalam identitas visual yang dirancang.

b. Warna dalam logo dapat menjadi warna dasar yang dapat dikembangkan menjadi skema warna tertentu.

c. Konfigurasi atau komposisi dari logo dapat dijadikan dasar untuk membangun struktur komposisi (grid) ataupun dasar pengaturan elemen-elemen (seperti tipografi).

\section{Ucapan Terima Kasih}

Penulis mengucapkan terima kasih kepada segala pihak yang terlibat dalam perkuliahan Studio Utama 3, terutama Felicia Kristella selaku mahasiswa yang proses perancangannya dijadikan obyek pembahasan dalam artikel ini; dan Helenna Ang dan Sharon Angelina selaku mahasiswa dari Program Studi Teknologi Pangan yang produknya menjadi entitas dalam proses perancangan ini. Penulis juga ingin mengucapkan terima kasih kepada tim pengajar yang terlibat dalam Studio Utama 3: Siswanto Sidharta, Sutoppo Singgih, Rerry Isfandriani dan Meutia Parahita. Tak lupa Penulis juga mau mengucapkan terima kasih kepada dosen Program Studi Teknologi Pangan yang membantu dalam mengembangkan produk Ubibu, Adolf J. N. Parhusip dan Yuniwaty Halim. 


\section{Daftar Pustaka}

Bardell, David. "Being a Dynamic Brand." Creative Bridge 20 September 2017 https://www.creative-bridge.com/blog/being-a-dynamic-brand/.

Budianto, Arif. "Kenapa Ubi Cilembu Manis Hanya Ketika Ditanam Di Sumedang?" Sindonews.com, MNC Media, $19 \quad$ Oktober 2018. https://daerah.sindonews.com/berita/1347558/174/kenapa-ubi-cilembu-manishanya-ketika-ditanam-disumedanghttps://daerah.sindonews.com/berita/1347558/174/kenapa-ubi-cilembumanis-hanya-ketika-ditanam-di-sumedang.

DesaCilembu.com. "Mitos Ubi Cilembu Sumedang." DesaCilembu.com https://www.desacilembu.com/2014/08/mitos-ubi-cilembu-sumedang.html.

Dundes, Alan. "Defining Identity through Folklore." Journal of Folklore Research, 1984, pp. 149152, https://www.jstor.org/stable/3814550?seq=1.

Expobia.id. "Cerita Mistis Di Balik Rasa Manis Ubi Cilembu Legenda." Expobia.id http://www.expobia.id/2017/02/cerita-mistis-di-balik-rasa-manis-ubi-cilembulegenda-kenapa-ubi-cilembu-rasanya-manis.html.

Fenech, $\quad$ Rob. $\quad$ "Morphological Matrix." Robfenench.Co.Uk https://www.robfenech.co.uk/morphological-matrix/.

Hananto, Brian Alvin. "Identitas Visual Digital Brand Dalam Sosial Media." SENADA (Seminar Nasional Desain Dan Arsitektur), vol. 2, 2019, pp. 56-61. https://eprosiding.stdbali.ac.id/index.php/senada/article/view/105https://eprosiding.stdbali.ac.id/index.php/senada/article/view/105.

---. "Perancangan Identitas Visual Dan Desain Kemasan Produk Makanan (Studi Kasus: Fibble)." GESTALT, vol. 1, no. 1, 2019, pp. 77-94, doi:https://doi.org/10.33005/gestalt.v1i1.21.

---. "Tinjauan Karya Desain Poster Quotes Dalam Mata Kuliah Tipografi Dasar." Jurnal Desain, vol. 6, no. 03, 2019, pp. 195-206, doi:http://dx.doi.org/10.30998/jd.v6i3.3350.

Hidayat, Beni et al. "Characterization of Sweet Potato Flour (Ipomea Batatas L.) Var. Shiroyutaka and Assesment of the Potential as Alternative Carbohydrate Source for Food Product." Jurnal Teknologi dan Industri Pangan, vol. 18, no. 1, 2007, pp. 32-39, https://journal.ipb.ac.id/index.php/itip/article/view/373.

JPNN. "Kang Emil Pengin Identitas Ubi Cilembu Terlindungi." JPNN.Com, PT. Jaringan Pemberitaan Nusantara Negeriku, 13 April 20182018. https://www.jpnn.com/news/kang-emil-pengin-identitas-ubi-cilembuterlindungi?page=1https://www.jpnn.com/news/kang-emil-pengin-identitas-ubicilembu-terlindungi?page $=1$.

Jury, David. What Is Typography?(Essential Design Handbooks). RotoVision SA, 2006. 
Kunjana, Gora. "Fasilitasi Hukum Hingga Modal, Identitas Ubi Cilembu Perlu Terlindungi." Investor Daily Indonesia, Berita Satu Media Holding, 13 April 20182018. https://investor.id/national/fasilitasi-hukum-hingga-modal-identitas-ubi-cilembuperlu-terlindungihttps://investor.id/national/fasilitasi-hukum-hingga-modal-identitasubi-cilembu-perlu-terlindungi.

Landa, Robin. Graphic Design Solutions. 4th edition, Wadsworth Cengage Learning, 2011.

Mahmudatussa'adah, Ai. "Komposisi Kimia Ubi Jalar (Ipomoea Batatas L) Cilembu Pada Berbagai Waktu Simpan Sebagai Bahan Baku Gula Cair Chemical Composition of Cilembu Sweet Potato (Ipomoea Batatas L) at Various Storage Time as Raw Material of Liquid Sugar." Jurnal Pangan, vol. 23, no. 1, 2014, pp. 53-64, http://jurnalpangan.com/index.php/pangan/article/view/51.

May, Tom. "The Beginner's Guide to Flat Design." 10 Desember 2018 https://www.creativebloq.com/graphic-design/what-flat-design-3132112.

Oyserman, Daphna et al. "Self, Self-Concept, and Identity." Handbook of Self and Identity, edited by Mark R. Leary and June Price Tangney, 2nd edition, Guilford Press, 2012, https://books.google.co.id/books?id=fa4 5xN9c5wC.

Samara, Timothy. Design Elements: A Graphic Style Manual. Rockport Publishers, 2007.

Wheeler, Alina. Designing Brand Identity. 3rd edition, John Wiley \& Sons, 2009. 